\title{
Mental health care of children and adolescents in Serbia: Past steps and future directions
}

\section{Dear Editor:}

Child and adolescent psychiatry (developmental psychiatry) is a relatively young and new discipline. With the advancement of clinical knowledge, research, education and professional activities, this field is continually being enriched and is a challenge for mental health professionals. It was developing in Serbia for the past fifty years and now represents a separate professional discipline which encompasses specific diagnostic procedures, treatment, prevention, rehabilitation and research of disorders of emotional, social and cognitive development of children and adolescents.

\section{HISTORICAL BACKGROUND}

The first mental health facilities for children and adolescents in Serbia were situated inside institutions for adult neuropsychiatry, or more rarely as parts of pediatric, psychological or special education services. The first department for child neuropsychiatry was founded in Belgrade in 1949 (Tadic, 1992; Ispanovic Radojkovic \& Tadic, 1996). Along with opening of services such as outpatient and inpatient units for child and adolescent psychiatry, education of local professionals was taking place abroad (primarily in Great Britain and France). A significant contribution to the psychosocial approach to child and adolescent mental health care was introduced at the Institute of Mental Health in Belgrade since 1963, leaning on the model of mental health care at the $13^{\text {th }}$ arrondismant (municipality) in Paris. Following that model, the Department for comprehensive mental health care of children and adolescents on the territory of the Old city municipality was founded (central quarter of the city, on the territory where the Institute of Mental Health is situated) (Popovic-Deusic et al., 2002).

Most experts in the field of child and adolescent psychiatry in Serbia are members of the Society for Child and Adolescent Psychiatry and Allied Professions of Serbia (DEAPS). DEAPS is an internationally known society, a member of international organizations such as European
Society for Child and Adolescent Psychiatry (ESCAP) and International Association for Child and Adolescent Psychiatry and Allied Professions (IACAPAP).

During the last decade of the twentieth century, a subspecialty in child neuropsychiatry was introduced. Department for Psychiatry at the School of Medicine, University of Belgrade, introduced a separate residency in child and adolescent psychiatry in 1994. Since then, about twenty child psychiatry specialists were educated in Serbia, and about ten more are in training (subspecialty in child neuropsychiatry does not exist anymore).

\section{DEMOGRAPHIC DATA ON CHILDREN AND ADOLESCENTS}

Population of Serbia without Kosovo and Metohija in 2002 was 7498001, according to data of the Serbian Institute for Statistics. Out of that number, 342344 $(4.56 \%)$ are children aged 0-4 years, 394596 (5.26\%) have 5-9 years, $439830(5.86 \%) 10-14$ years, and 495651 (6.61\%) are 15-19 years old (Republic Office for Statistics, 2003).

Most services dealing with mental health problems of children and adolescents are situated in big cities and regional centers. The significant problem at the state level is an insufficient number of child psychiatrists, since the specialized training in child psychiatry was introduced fourteen years ago. However, the total number of psychiatrists (neuropsychiatrists) in Serbia is sufficient, and is approximately 947 (336 in Belgrade alone). On 100000 people there are 2.7 psychiatrists and 9.93 neuropsychiatries. Many of them are completely dedicated to work with children and adolescents, and in that way, deficit of child psychiatrists is being reduced (Ministry of Health of the Republic of Serbia, 2007).

The mental health care and mental health promotion of the population in Serbia, and particularly of children and adolescents is one of priorities of the Ministry of Health which in 2003 established the National expert group for youth development and health in the Republic of Serbia. During 2006 the Ministry of Health developed and pub-

Epidemiologia e Psichiatria Sociale, 18, 3, 2009 
lished Strategy for youth development and health with the action plan (Ministry of Health of the Republic of Serbia, 2006).

\section{SER VICES FOR MENTAL HEALTH CARE OF CHILDREN AND ADOLESCENTS}

The first professional help for children with mental health problems is given at preschool and school facilities and primary health care centers (pediatric services within health centers). From there, after professional assessment, most of the children with evident developmental problems (as well as children with high-risk of developing problems) are referred to developmental counseling services or youth counseling services, which are parts of pediatric services in primary health care centers and are functioning as teams consisting of pediatrician, psychologist, social worker, special pedagogue and nurse.

Most interventions are completed within developmental counseling services (at the moment there are 40 of them, each covering about 80000 children, from 0 to 10 years of age) or youth counseling services (there are 30 of them in Serbia). If problems are beyond their liability, children and adolescents can be referred to local social services, specialized clinics, and departments for mental health care of children and adolescents with developmental problems within large hospitals (secondary health care). When the problems are beyond the competence of secondary health care, children are directed towards tertiary health care such as specialized departments for child and adolescent mental health care at university clinics (Ispanovic-Radojkovic \& Tadic, 1996). There are five of them in Serbia (in the biggest cities), with an overall number of 80 beds, which comes down to one bed per 300000 children and adolescents. However, the number of day care hospitals is significantly bellow needs of the population. There is one such hospital for children up to 12 years of age, and two for adolescents, all located in Belgrade (Popovic-Deusic et al., 2002; Ispanovic-Radojkovic \& Tadic, 1996). Modern day hospital for adolescents was opened at the Institute of Mental Health in Belgrade at the beginning of 2008, with the capacity of 30 adolescents aged 15-25. The treatment is comprehensive and mainly based on milieu psychotherapy. Following the need for proper child abuse and neglect prevention, diagnosis and treatment, a unique Unit for mental health care of abused children and adolescents was developed within Institute.

\section{MENTAL HEALTH OF CHILDREN AND ADOLESCENTS}

Mental health of Serbia's population deteriorated a great deal during last $10-15$ years. The increase in prevalence of mental disorders in children and adolescents is related to the years of stress and traumatic experiences to which the population had been exposed in the last decade of the XX century (four wars in the region; hyperinflation in 1993; three and a half years of UN sanctions against Serbia; NATO bombing of 1999 that lasted for 11 weeks; financial crisis and a high-rate of unemployment; complex period of social transition and cultural disintegration together with anomy and alienation, a process which is now taking place). These traumatic events led to deprivation, poverty and demoralization of citizens. The prolonged stress caused various psychological consequences, predominantly expressed in vulnerable segments of the population, such as children and adolescents. There is an increase of depressive disorders, suicide rate, substance abuse, psychosomatic disorders, delinquency, along with a higher death rate in lower age groups (Lecic-Tosevski \& Draganic-Gajic, 2004; Pejovic- Milovancevic et al., 2002).

Territory of Serbia had been struck by several waves of refugees and internally displaced persons (IDPs), always with high percentage of children and youth. At the beginning of wars in 1990 about 700000 persons were forced to find refuge in Serbia, escaping from Bosnia and Herzegovina and Croatia. A new wave of refugees followed in 1995, when about 250.000 persons deflected to Serbia from Croatia. After the bombing in 1999, 250.000 people were forced to leave the territory of Kosovo, as internally displaced persons. It is well known that refugees and IDPs are specifically vulnerable population; a large number (approximately half a million) of them still lives on the territory of Serbia, which requires special efforts and measures for the purpose of their mental health care (Lecic- Tosevski \& Draganic-Gajic, 2004).

Our clinical experience and studies indicate that a growing number of children and adolescents have psychological problems, or manifest clear psychopathology. The most frequent psychopathological manifestations include depressive conditions (frequently with suicidal behavior) and behavioral problems (such as substance abuse, peer violence and delinquent behavior) (PejovicMilovancevic et al., 2002; Popovic-Deusic et al., 2002). Research conducted on our adolescent population (highschool population in urban area - Belgrade) has shown that one third of adolescents belong to the borderline and high-risk groups. Study carried out on the sample of stu-

Epidemiologia e Psichiatria Sociale, 18, 3, 2009 
dents (also urban area - Belgrade) has shown similar results (Ministry of Health of the Republic of Serbia, 2006). The developmental difficulties such as establishment of a stable and mature identity are also frequent $14.5 \%$ of the children in general population and $62 \%$ of the refugee population have moderate or severe psychological problems and disorders, as a consequence of traumatic experiences and chronic stress to which they were exposed (Lecic-Tosevski et al., 2007).

Data collected through a self-report survey (the Social and Health Assessment - SAHA; Weissber et al., 1991), administered in 2007 to 882 adolescents in Belgrade (22\% adolescents were 15 years old, 60\% 16-18 years, $18 \%$ over 18 years but still in high school, with gender distribution $64 \%$ girls and $36 \%$ boys). Results have shown that $20 \%$ of the sample felt that their health should be improved; $10 \%$ reported great concern about their own health and $14 \%$ that they did not feel well in past 30 days. In addition to that $21 \%$ of adolescents felt tired every day, $19 \%$ were nervous about social environment, $15 \%$ felt depressed, $12 \%$ lonely, $11 \%$ that nobody could help them, $7 \%$ reported lack of life satisfaction and $6 \%$ that bad things happened due to their feeling of guilt. The most common health complaint was headache, with $18 \%$ of adolescents feeling it on a regular basis.

\section{Future directions}

The National action plan for the development of mental health care and youth development is dealing with the basic strategies for prevention of mental disorders and mental health promotion through the following:

1) expanding the preventive and therapeutic potentials of primary health care services through additional training of the existing personnel (general practitioners, pediatricians and their associates) about mental health problems of youth (opening of youth health services);

2) cooperation of youth health services with mental health services in each municipality, as well as with tertiary psychiatric institutions;

3) supporting programs and projects of non-governmental organizations for psychological care of the youth;

4) programs against stigmatization of youth with mental disorders

5) creating possibilities for psychological support and help for the youth outside medical and psychiatric institutions (in schools, students homes and boardingschools), but also through opening consultancies in cities - outside institutions;
6) training young people and developing peer support;

7) primary prevention of mental disorders of youth and mental health promotion through the educational system (additional briefing and training of teachers, pedagogues, school psychologists, and parents) and all forms of mass communication (informing the public about specificities of adolescence as a developmental period, and about needs and possibilities for adolescents to get psychological support).

The current level of development and organization of the health system in Serbia ensures necessary conditions to introduce certain methodological adjustments to the concept of health centers according to the needs of youth (Lecic-Tosevski et al., 2005). A special accent is placed on outgrowing the health challenges faced by young people, who are already in an unfavorable social and economic position. Teamwork between sectors of significance for health and development of youth should be the path for creating an environment where young people will have the right conditions for adequate physical and mental health, physical and emotional well-being, freedom from abuse and molestation, along with opportunities to lead healthy life styles.

Since suicide and violence are widely spread among children and adolescents, the Institute of Mental Health is just about to start programs for prevention of these two major problems, in cooperation with the Ministry of Health.

\section{CONCLUSION}

Development of services for mental health care in Serbia is in accordance with contemporary trends in the world. There is a network of services for the youth with mental health problems within primary health care services, as well as in hospitals - a network which should certainly be further developed and improved. However, taking into account the last 15 years of acute and chronic stress and general crisis of the society, as well as the present situation of social transition, children and adolescents of Serbia are under great risk of developing mental disorders. This is why efforts should be focused on intensifying primary preventive activities, in order to improve and promote mental health of children and adolescents. To reach that goal it is necessary to support efforts and activities of the National Committee for Mental Health of the Ministry of Health of the Republic of Serbia and implement the Strategy for Development of Mental Health Care, particularly in the field which relates to opening of new services for mental health care of chil- 
dren and adolescents in the community, enhancing preventive and therapeutic potentials of primary health care and peer-assistance for the youth with psychological problems (Lecic Tosevski et al., 2007).

\section{Milica Pejovic Milovancevic Smiljka Popovic Deusic Dusica Lecic Tosevski* Saveta Draganic Gajic **Institute of Mental Health WPA Zonal Representative for Central Europe Palmoticeva 37 \\ 11000 Belgrade (Serbia) Fax: +381-11-3231 333 \\ E-mail: dusica.lecictosevski@eunet.rs \\ Received 26.01.2009 \\ Revised version received 24.02.2009 \\ Accepted 14.03.2009 \\ Ispanovic Radojkovic V., Tadic N. (1996). Child and adolescent psy- chiatry. In Child and Adolescent Psychiatry in Europe: Historical}

\section{REFERENCES}

Development, Current Situation, Future Perspectives (ed. H. Remschmidt and H. van Engeland), pp. 285-297. Springer-Verlag: Berlin.

Lecic-Tosevski D., Draganic-Gajic S. (2004). The Serbian experience. In Disasters and Mental Health (ed. J.J.Lopez-Ibor, G.N. Christodoulou, M. Maj, N. Sartorius, A. Okasha), pp. 247-255. John Wiley \& Sons: New York.

Lecic-Tosevski D., Curcic V., Grbesa G., Ispanovic Radojkovic V., Milicevic Kalasic A., Stankovic Z, et al. (2005). Zastita mentalnog zdravlja u Srbiji - izazovi i resenja [Mental health care protection in Serbia - challenges and solutions]. Psychiatry Today 37, 17-25.

Lecic-Tosevski D., Pejovic-Milovancevic M. \& Popovic-Deusic S. (2007). Reform of mental health care in Serbia: Ten steps plus one. World Psychiatry 6, 51-55.

Ministry of Health of the Republic of Serbia (2006). Strategy for Youth Development and Health in the Republic of Serbia. Ministry of Health of the Republic of Serbia: Belgrade.

Ministry of Health of the Republic of Serbia. (2007). Strategy for the Development of Mental Health Care. Ministry of Health of the Republic of Serbia: Belgrade.

Pejovic-Milovancevic M., Ispanovic-Radojkovic V., Vidojevic O., Kalanj D., Marunic V., Radosavljev J. et al. (2002). Model zastite dece od zlostavljanja i zanemarivanja [The model of child abuse and neglect protection]. Psychiatry Today 34, 117-132.

Popovic-Deusic S., Aleksic O. \& Pejovic-Milovancevic M. (2002). Razvojna psihijatrija u nasoj sredini [Developmental psychiatry in our region]. Psychiatry Today 34, 7-12.

Republic Office for Statistics (2003). Statistical Report, pp 34-66. Republic Office for Statistics: Belgrade.

Tadic N. (1992). Decija i adolescentna psihijatrija [Child and adolescent psychiatry]. Naucna knjiga, Beograd. pp 12-23.

Weissberg R.P., Voyce C.K., Kasprow W.J., Arthur M.W. \& Shriver T.P. (1991). The Social and Health Assessment. Chicago, IL. 